\title{
Stuck and sticky in mobile academia: reconfiguring the im/mobility binary
}

\author{
Charikleia Tzanakou $^{1}$ (D) Emily F. Henderson ${ }^{2}$ \\ Accepted: 26 March 2021 / Published online: 7 July 2021 \\ (C) The Author(s), under exclusive licence to Springer Nature B.V. 2021
}

\section{Reconfiguring the im/mobility binary}

Globalisation and higher education expansion have accelerated the mobility of academics in the past few decades, though mobility has always inhered to the profession; the 'wandering scholar' is part of the cultural baggage of academia (Kim, 2009). Academic mobility is romanticised in policy and academic discourse as a positive force (Fahey \& Kenway, 2010; Kim, 2017; Robertson, 2010), and mobility has often been investigated as a resource for career development and progression of individuals or as a contributor to national economic growth and advancement (brain-drain/gain) (Fahey \& Kenway, 2010; Gibson \& McKenzie, 2011; Tzanakou \& Behle, 2017). In other words, academic mobility has tended to be explored within a human capital framing, presenting academics as neoliberal individuals being shaped by neoliberal higher education institutions and national research policies. There has tended to be a valorisation of mobility and a denigration of immobility in research, policy and practice, with both of these terms defined in relatively narrow terms and closely aligned with the geopolitical hierarchies that structure both national HE systems and the international HE labour market. A small body of scholarship has been critiquing academic mobility discourses for some years now, but owing to the disciplinary dispersal of research in this area, there has been little scope to bring this critical work together. The field of academic mobility studies is still nascent, and research in this area is spread across a number of disciplines, most notably higher education studies, migration studies and human resource management studies. However, interest in this area is growing, with many ongoing studies focusing on aspects of academic mobility, and work in this area is consolidating around common themes, particularly in relation to power, mobile subjectivities, and experiences of mobility. This scholarship is starting to be known as the Critical Academic Mobilities Approach (CAMA) (Burford et al., 2021; Henderson, 2019). This special issue is situated within the remit of CAMA and indeed lays new ground for critical analysis of academic (im)mobilities, given the theoretical focus of the special issue.

Charikleia Tzanakou

ctzanakou@brookes.ac.uk

2 University of Warwick, Coventry, UK 
The special issue focuses on interrogating a binary that is often drawn in research, policy and practice, where mobility is defined in relation to immobility. In the special issue, we have explored the assumptions and norms underpinning the concepts of mobility and immobility, and therefore query the conceptual certainties that are inherent to discourses around academic mobility itself. In short, we have aimed to capture ways in which mobility and immobility intersect and overlap, where an academic may be both mobile and stuck, for instance. While the special issue was developed and largely produced in advance of the COVID-19 pandemic, the papers nonetheless have taken on a new resonance when read against the unfolding of this phenomenon on the world stage. Travel restrictions have stopped mobile academics in their tracks, including leaving academics stranded while on their travels and disrupting the fine balance of long-distance living-working arrangements that have become the hallmark of the internationalising academic profession. The profession's reliance on international mobility in order to function - particularly at an elite level where top-ranked universities compete to attract global talent - has been exposed by the pandemic. At the same time, mainstream academic discussions are now centring on the imperative of reducing the carbon footprint of academic mobility (Arsenault et al., 2019). These two eventualities bring to the fore urgent questions of how the profession can reach for alternative forms of mobility, particularly in terms of virtual mobility, and the consequences of managing a hyphenated state of mobility and immobility. These concerns are addressed throughout the special issue in a way that is prescient of world events that had not occurred at the inception of the projects reported on in the papers.

One of the key aims of the special issue was to bring together a range of critical studies of academic mobility, in order to showcase work in the field and to provide a reference point for further scholarship. The special issue brings together studies of a variety of different types and forms of academic mobility, illustrating the diverse understandings of this term. Academic mobility includes academics working at any stage of the career, with a special branch of academic mobility scholarship focusing on doctoral mobility. The definition of 'academic' is itself blurred, as some studies use the term to refer to doctorate holders or individuals with equivalent experience, or those teaching and/or researching in universities and higher education institutions, and due to different qualification requirements in different national contexts, these groups may not be contiguous. Moreover, the definition of 'mobility' is also blurred, as mobility can include a range of activities spanning from permanent migration, moving for the purposes of a qualification or a job to short-term mobility which may include not only research trips or residencies lasting months but also shorter trips such as conference attendance and institutional visits. Different forms of mobility may occur concurrently, such as a migrant academic who is now based in the UK, who then transfers to another university for a residency, and then attends a conference in another part of that country during that residency. As such, forms of mobility are rarely discrete. In addition to there being different forms of mobility, it is also necessary to query the unspoken assumption that academic mobility involves international travel across borders. This version of mobility omits forms of mobility that involve moving within borders (Sautier, 2021) or operating in an international team environment while staying in one place, such as working on an international collaborative project (Tzanakou, 2020). These forms of mobility are included in the special issue and they hold up a critical mirror to the normative assumptions of academic mobility as international travel.

The map of academic mobility research is itself worthy of a critical examination. While the special issue sought to include a range of different locations within its remit, there is a strong bent in the papers towards Europe (Greece, Tzanakou (2020); Switzerland, Sautier (2021); 
UK, Pustelnikovaite (2020)) and Asia (Japan, Morley et al. (2020); Singapore, Chou (2020); Thailand, Burford et al. (2021)), both of which regions are strongholds of academic mobility policy and research. Several papers focus on national policy contexts and/or countries that function as mobility destinations. Only one paper is a transnational study incorporating movement to and from several countries (Henderson, 2020). The papers in the collection reinforce the reality that the pandemic has also exposed: that free, unrestrained mobility has been a popular myth circulating within and shoring up the norms of the academic profession. Mobility is always and has always been contained within the structures of national borders and policy frameworks, and this is also evidenced in the special issue. Foregrounding the role of the nation state in facilitating — or even requiring - academic mobility is an important move for critical academic mobility research, as doing so removes the illusion that mobility occurs above national constraints, within a borderless global HE sector. However, arguably a focus on a single nation state (and in some cases a region such as the European Research Area) means that the comparative perspective is neglected, though the special issue as a whole operates as a comparative kaleidoscope.

The focus on single nation state studies is related to one of the other key aims of the special issue, namely, to present in-depth, qualitative studies of academic mobility. The field of academic mobility research has been dominated by survey research and secondary data analysis, which has provided useful information on the patterns and flows of mobility. However, there has been less of a focus on the lived experiences of mobile academics, for which qualitative data collection methods are more suitable. All of the studies in this collection used qualitative methods, specifically interviews, either as the only form of data collection or in combination with another method (questionnaire survey, Chou, 2020), Tzanakou, 2020); diary data collection, Henderson (2020). Each of the studies was relatively small scale due to this methodological orientation, though the special issue as a whole incorporates a total of 332 interview participants. The single nation state focus of most of the papers is revelatory of the nascence of the critical academic mobility field and of its status in the research funding landscape. While all of the projects included in the special issue received funding, the majority of the funding either took the form of a doctoral scholarship or an internal institutional funding scheme. In a field that is characterised by reflexivity due to the 'meta' focus, it is important to reflect on the funding conditions that contribute to the prevalence of particular study designs. However, these conditions notwithstanding, the in-depth studies represented in the special issue provide key insights into the processes and experiences of academic mobility - the 'hidden narratives of mobility' (Morley et al., 2018, p. 2) - and allow us to interrogate the mobility/immobility binary through the textual analysis of participants' verbal negotiations of this binary.

The genesis of this special issue was a research network formed to consolidate the work on critical academic mobilities. AMIN-Academic Mobilities and Immobilities Network-was formed as a cross-departmental endeavour at the University of Warwick (funded by the Institute of Advanced Study and the Faculty of Social Sciences Research Development Fund), with the special issue editors having been two of the founding convenors. The majority of the authors in the special issue have been involved in AMIN in terms of presenting in network events and conference panels, with others joining through our wider networks. The special issue itself has been produced by and through different forms of academic mobility, including the origins of AMIN's funding lying in the University of Warwick's internationalisation strategy, and short-term mobility that included special issue authors travelling by long-haul flights and overnight buses alike to various locations to present on the work. Though the 
papers in the special issue have not engaged in personal reflection on authors' positionality in relation to academic mobility, we have all been personally involved in different forms of academic mobility and have developed our stances on the field through our personal experiences of dis/alignment with the im/mobility binary. AMIN has now travelled through to print form in this special issue and no longer exists in its original form, with three of the convenors having moved university, including two having relocated to other countries. However, the changes to academic working imposed by COVID-19 have led to a reconceptualization of the network as a truly international group; at the time of writing, this is being set up with an international convening committee and an online events programme.

\section{'Stuck' and 'sticky'}

Due to the disciplinary dispersal of academic mobility research, there is no theoretical canon for this field. This is in some senses an advantage, as the terrain is open for radical theoretical exploration, without the constraints of theoretical orthodoxies and related gatekeeping. However, there is also a disadvantage, in that research on academic mobility has tended to be somewhat atheoretical, though this lacuna has been to an extent addressed within scholarship under the CAMA umbrella (Henderson, 2019). There are of course many different ways of working with theory - and ideas of what counts as theory - and some of these disciplinary orientations towards 'theory' are exemplified in this special issue. Working with theory can involve locating theoretical frameworks in advance of writing and then analysing data alongside the concepts located in the framework. Alternatively, thematic coding of data can reveal overarching concepts that are then built into theoretical frameworks as a result. There are other options which lie between these two positions, drawing connections between literature, 'theory' and data. When conceptualising this special issue, as editors we wanted to make a theoretical contribution to the field, but we also did not wish to impose a particular theory or way of working with theory upon the contributors. We arrived at the idea of providing two evocative conceptual tools which authors could then work with in their own way. 'Stuck' and 'sticky' appealed to us as terms that are common in everyday parlance; we deliberately chose the terms 'sticky' and 'stuck' to deploy their negative connotations in terms of feeling uncomfortable and trapped or of "'being stuck" and having one's life on hold' (Lahad, 2012, p. 183). These tools were then presented to the authors as a challenge and an invitation to engage in playful conceptual thinking. The process was itself at times both sticky and stuck, as we became aware of the challenges involved in asking authors to play with concepts that were both open and fixed (and asking reviewers to come on board with this too). However, the result is a special issue that is truly coherent in terms of both topic and theoretical contribution. The different theorisations of 'stuck' and 'sticky' have departed in directions that have stretched these concepts beyond our imagined possibilities when we crafted the proposal, and joined together, they form a flexible but structured framework that we hope others will put to use for future work in this area. In this section of the special issue, we give an overview of the 'stuck' and 'sticky' framework that emerges from the papers when they are explored as a collection.

Our selection of 'stuck' and 'sticky' emerged from the use of these terms in existing studies of mobility and migration, often as in-passing references rather than fully elaborated conceptualisations. Being 'stuck in place', for instance, tends to denote rooted communities who are considered socially and geographically immobile (e.g. Boyer et al., 2017); the term has also been used to refer to 'stuck policy places' (Pillow, 2015, p. 64). 'Stickiness' has been used 
to refer to the ways in which individuals become anchored to particular contexts such as countries and workplaces (e.g. Coey, 2013) and to frame a challenge to the notion of migration as 'fluid' (Costas, 2013). In this special issue, we explore the notion of being 'stuck in place' while in a situation of mobility, for example, being unable to move on from a particular context or being 'stuck' in a chain of postdoctoral positions or when migrant academics are 'stuck in hourly paid part-time jobs' (Kim, 2009, p. 397). Our development of 'sticky' was inspired by Ahmed's (2004, 2009, 2014) uses of this concept (see Henderson (2020) and Tzanakou (2020) in this special issue for a fuller explanation). Academic mobility can be considered 'sticky' when an academic relocates to a new country context but in some way retains an imprint of the previous context in their identity or work practices or when the mobility imperative is countered with personal circumstances which restrict mobility. Ackers (2005) challenges the notion of fluidity in constructions of mobile subjects, noting that mobility tends to 'become more "sticky" over the life course' owing to increased family and community commitments (p. 114) (see also Henderson \& Moreau, 2020; Tzanakou, 2017). Mobility involves " "sticky" encounters with the world' (Parker \& Weik, 2014, p. 178), where bodies come into contact with different surfaces and other bodies and sometimes get it right, sometimes wrong (Barnett \& Phipps, 2005).

\section{Sticky and stuck in mobile academia-a 'sticky-stuck' multi-level conceptual framework}

The papers in this special issue have contributed towards developing a 'sticky-stuck' multilevel conceptual framework that brings together mobility narratives interacting dynamically with framings at macro, meso and micro level, which we outline below.

i) The dominant discourse of internationalisation

Academic mobility is framed at a macro level by the sticky discourse of internationalisation (Morley et al., 2020). Internationalisation is sticky because positive affect is stuck to this discourse but also because the discourse is attractive and sticks to higher education policy and to individuals who become caught up in living by this discourse (ibid. ; Tzanakou, 2020). Within this discursive frame, destinations, higher education contexts and individuals operate in interconnected ways so that they are inextricable from each other.

ii) Destinations and higher education contexts

At a meso level, destinations are more or less attractive to academics, for personal reasons such as proximity to (or distance from) family or the reputation of the destination itself as being beautiful, warm or exotic (Burford et al., 2021; Chou, 2020). Destination attributes also include - and therefore overlap with - the national higher education context as well as the positioning of the national higher context in the international hierarchy (Burford et al., 2021; Pustelnikovaite, 2020) but also based on comparative conditions between the academic job market in the previous location versus the new location (Burford et al., 2021; Pustelnikovaite, 2020). Higher education contexts operate as policy spheres within destinations, for example, impelling early career academics to leave in order to return and stay (Sautier, 2021).

Once located within a destination and higher education context, this is where some of the sticky and stuck while mobile patterns occur. A destination and/or higher education context may be experienced as so appealing — sticky — that an academic may decide to stay (Chou, 2020). 
Alternatively, a destination and/or higher education context may be attractive, but it may turn out to be challenging for an academic to adhere to the sticky destination. Some destinations are slippery, for example, based on the challenge for expatriates of paying for living expenses or obtaining a permanent contract (Chou, 2020). Some academics seek employment in other countries because they are 'locked out' of academia in their countries of origin, due to their specialism or the lack of openings in that country (Pustelnikovaite, 2020). However, when they reach the new destination, they find they become 'locked in' or stuck, because their career has been shaped by the destination country's higher education context in a way that does not appeal in other systems (e.g. privileging journal articles over a book) (ibid.). The stuckness may only become apparent when an academic tries to move on, engage in further mobility, where they find they are affected by career stickiness (Tzanakou, 2020) or career stuckness (Burford et al., 2021). The previous move may stick to an academic's CV and career trajectory, particularly if the destination is ranked low in the international higher education hierarchy, meaning that mobility becomes an obstacle to further mobility (ibid.).

\section{iii) Individual mobile academics}

At a micro level, the individual academic is traditionally seen as operating as an agentic individual, who is able to unstick themselves from any context and move on (Morley et al., 2020) - and even to operate without context (Kim, 2009). However, our theorisation, which allows space for agency but clearly demarcates social structures, recognises that mobile academics are sticky individuals who operate within constraints and limitations posed by destinations, higher education systems and international discourses shaping the priorities of the global higher education sector. Mobile academics are engaged in parallel but intertwined career and mobility trajectories, which are comprised of multiple types of mobility and decisions to remain in place. Each mobility decision needs to be situated in these parallel career and mobility trajectories.

Moreover, we conceptualise the individual as a relational, affective being. Individuals' careers are shaped by affective stickiness, where emotions and attachments contribute to the shaping of careers, including decisions to stay in place (Tzanakou, 2020). Mobility decisions are shaped by relationships to people and places. This includes the decision to relocate (semi-)permanently or for a number of years (Burford et al., 2021; Pustelnikovaite, 2020; Tzanakou, 2020) and to engage in shorter term mobility such as a postdoctoral fellowship (Sautier, 2021) or a conference (Henderson, 2020). In terms of the shorter term mobility, academics' attachments are situated on a spectrum of sticky-stretchy, where those with stickier attachments remain in place (Tzanakou, 2020) or struggle to maintain mobility and those with stretchier attachments are socially positioned in a way that they can remain on the move (Sautier, 2021). Attachments to home as an impediment to mobility include academics' relational attachments to others, in the form of care. Care is sticky, and academics are attached to home and to those they care for by sticky, stretchy strings (like chewing gum) (Henderson, 2020). These strings are comprised of sticky care duties, where the primary carer is irreplaceable in the home and therefore stuck, and sticky emotional attachments where ideal parenting (especially mothering) is predicated on physical presence (ibid.).

\section{iv) Mobility narratives}

Finally, each academic has their own mobility story, in which they express their participation in academic mobility and the sticky discourse of internationalisation and make sense of the 
dynamic interactions between macro, meso and micro levels; even 'stuck' academics who are engaging in limited mobility in any traditional sense are aware of the global discourses (Tzanakou, 2020) and absorb the cultural baggage of the wandering scholar. Mobility narratives represent and/or produce the mobility phenomenon. In this sense, academics can also become stuck in their own narratives of stuckness, where they narrate themselves into further stuckness (Burford et al., 2021), as well as potentially narrating themselves into being unstuck (Tzanakou, 2020; Morley et al., 2020).

In the conceptualisation of the mobile academic presented in this special issue, each mobility decision (for any type of mobility) is a sticky negotiation between affective and relational attachments, career planning, home and destination attributes, higher education contexts, dominant discourses of internationalisation and postcolonial hierarchies which structure the global higher education sector. While any study may focus on one of the aspects of this framework in particular, the overarching conceptual framework demands that mobility research takes the full picture into consideration, even when focusing on one aspect, so that a more holistic approach to researching academic mobility is achieved.

\section{Mobilising the academic mobility research field}

This special issue set out to showcase and consolidate critical research on academic mobilities and to make a theoretical contribution to the field in the form of a new conceptual framework that explores 'sticky' and 'stuck' aspects of mobility-and deconstructs the im/mobility binary. The papers in the special issue combine to present a picture of academic mobility that is neither rosy nor wholly pessimistic; perhaps we could say we have painted a realistic portrait of this cumbersome, joyous, painful, necessary aspect of the academic profession. The papers in the special issue have focused on in-depth studies of academic mobility, which have been for the most part single-country studies. This has enabled the special issue to explore the lived experiences of mobile academics and to acknowledge and analyse the national policy contexts that frame academic mobility. The contributions in the issue have spanned academic career stages, geographical regions, intersecting identity characteristics, types of mobility and approaches to working with theory in empirical work. The special issue thus aims to serve as a reference point for future research aiming to work within a critical academic mobility frame, with wider aspirations of influencing how academic mobility policy and institutional practices are developed and implemented.

The special issue also sets out further aims and possibilities for academic mobility research. While the projects represented in the articles were conducted before the COVID-19 pandemic, there are many synergies with academics' experiences of the pandemic. The 'stuck-sticky' framework provides a timely conceptualisation for experiences of being both mobile and immobile in new and unforeseen combinations of lived experience. We have identified a geographical limitation in the special issue, where the focus is on Europe and Asia. There is further potential to push at the map of academic mobility research, particularly exploring the effects of different imperial and colonial legacies as well as valorising south-south academic mobility within the research field. The special issue is also predominantly composed of singlecountry studies and arguably more multi-country comparative studies - underpinned by qualitative methodologies as well as quantitative-would enhance the knowledge base and reputation of this nascent field. However, this enters into the politics of external research funding for critical social sciences research. All of the contributions to the special issue used 
interviews within qualitative or mixed methods research designs. This was in itself a contribution to academic mobility research, where survey research and secondary data analysis has dominated. However, there is plenty of scope to enhance methodological innovation in this field and to take the opportunity offered by an emerging field - without too many gatekeepers in place - to engage in methodological experimentation and to make this field a cutting-edge site in this regard. The articles in the special issue have shown how academic mobility practices and policies are situated in social structures that result in the reinforcement of heightened inequalities in the academic profession; there is scope for further research in this area, particularly taking an intersectional analytical approach. Finally, the special issue has offered many different ways of reconsidering the im/mobility binary, and the contributors have presented a robust argument for exploring the blurred edges between mobility and immobility in the academic mobility phenomenon. It is our aspiration that future research, instead of shoring up the binary, will contribute to critiquing reductive conceptualisations of academic mobility.

Acknowledgements The special issue editors would like to recognise the work of the original AMIN convening group, Heike Behle, Xuemeng Cao, Emily Henderson, Charikleia Tzanakou and Stephanie Schnurr, and to thank the University of Warwick Institute of Advanced Study and Research Development Fund for funding this endeavour. The editors would like to thank Rosemary Deem and Susan Robertson for feedback on the initial special issue proposal and for encouraging us to push our thinking further, the journal editors and those who assisted with the publishing process, the reviewers who gave their time to improve the special issue and the contributors for their willingness to 'play' along with the sticky/stuck idea.

\section{References}

Ackers, L. (2005). Moving people and knowledge: Scientific mobility in the European Union. International Migration, 43(5), 99-131.

Ahmed, S. (2004). Affective economies. Social Text, 22(2), 117-139.

Ahmed, S. (2009). Embodying diversity. Problems and paradoxes for Black feminists, race ethnicity and education, 12(1), 41-52.

Ahmed, S. (2014). The cultural politics of emotion (Second edition). Edinburgh University Press.

Arsenault, J., Talbot, J., Boustani, L., Gonzalès, R., \& Manaugh, K. (2019). The environmental footprint of academic and student mobility in a large research-oriented university. Environmental Research Letters, 14(9), 095001.

Barnett, R., \& Phipps, A. (2005). Academic travel: Modes and directions. Review of Education, Pedagogy, and Cultural Studies, 27(1), 3-16.

Boyer, K., Mayes, R., \& Pini, B. (2017). Narrations and practices of mobility and immobility in the maintenance of gender dualisms. Mobilities, 12(6), 847-860.

Burford, J., Eppolite, M., Koompraphant, G., \& Uerpairojkit, T. (2021). Narratives of 'stuckness' among NorthSouth academic migrants in Thailand: Interrogating normative logics and global power asymmetries of transnational academic migration. Higher Education. doi:10.1007/s10734-020-00672-6 [see article in this Special Issue].

Chou, M.-H. (2020). Sticky and slippery destinations for academic mobility: The case of Singapore. Higher Education. doi:10.1007/s10734-020-00574-7 [see article in this Special Issue].

Coey, C. (2013). International Academics in English Higher Education: Practicing and capturing mobile careers. University of Liverpool. [PhD thesis].

Costas, J. (2013). Problematizing mobility: A metaphor of stickiness, non-places and the kinetic elite. Organization Studies, 34(10), 1467-1485.

Fahey, J., \& Kenway, J. (2010). International academic mobility: problematic and possible paradigms. Discourse: Studies in the cultural politics of education, 31(5), 563-575.

Gibson J. and D. McKenzie (2011). "Eight questions about brain drain," CReAM Discussion Paper Series 1111, Centre for Research and Analysis of Migration (CReAM), Department of Economics, University College London. 
Henderson, E. F. (2019). A PhD in motion: Advancing a critical academic mobilities approach (CAMA) to researching short-term mobility schemes for doctoral students. Teaching in Higher Education, 24(5), 678693.

Henderson, E. F. (2020). Sticky care and conference travel: Unpacking care as an explanatory factor for gendered academic immobility. Higher Education. doi:10.1007/s10734-020-00550-1 [see article in this Special Issue].

Henderson, E. F., \& Moreau, M.-P. (2020). Carefree conferences? Academics with caring responsibilities performing mobile academic subjectivities. Gender and Education, 32(1), 70-85.

Kim, T. (2009). Shifting patterns of transnational academic mobility: A comparative and historical approach. Comparative Education, 45(3), 387-403.

Kim, T. (2017). Academic mobility, transnational identity capital, and stratification under conditions of academic capitalism. Higher Education, 73(6), 981-997.

Lahad, K. (2012). Singlehood, waiting, and the sociology of time. Sociological Forum, 27(1), 163-186.

Morley, L., Alexiadou, N., Garaz, S., González-Monteagudo, J., \& Taba, M. (2018). Internationalisation and migrant academics: The hidden narratives of mobility. Higher Education, 76, 537-554.

Morley, L., Roberts, P., \& Ota, H. (2020). The affective assemblage of internationalisation in Japanese higher education. Higher Education. doi:10.1007/s10734-020-00593-4 [see article in this Special Issue].

Parker, M., \& Weik, E. (2014). Free spirits? The academic on the aeroplane. Management Learning, 45(2), 167181.

Pillow, W. S. (2015). Policy temporality and marked bodies: feminist praxis amongst the ruins. Critical Studies in Education, 56(1), 55-70.

Pustelnikovaite, T. (2020). Locked out, locked in and stuck: exploring migrant academics' experiences of moving to the UK. Higher Education. doi:10.1007/s10734-020-00640-0 [see article in this Special Issue].

Robertson, S. L. (2010). Critical response to Special Section: International academic mobility. Discourse: Studies in the Cultural Politics of Education, 31(5), 641-647.

Sautier, M. (2021). Move or perish? Sticky mobilities in Swiss academia. Higher Education. [see article in this Special Issue].

Tzanakou, C. (2017). Dual career couples in academia, international mobility and dual career services in Europe. European Educational Research Journal, 16(2-3), 298-312.

Tzanakou, C. (2020). Stickiness in academic career (im)mobilities of STEM early career researchers: an insight from Greece. Higher Education. doi:10.1007/s10734-020-00596-1[see article in this Special Issue].

Tzanakou, C., \& Behle, H. (2017). The intra-European transferability of graduates' skills gained in the UK. Journal of Ethnic and Migration Studies, 43(8), 1379-1397.

Publisher's note Springer Nature remains neutral with regard to jurisdictional claims in published maps and institutional affiliations. 